\title{
Família e projetos sociais voltados para jovens: impacto e participação'
}

\author{
Family and social projects aimed at young \\ people: impact and participation
}

\author{
Marianne Ramos FEIJÓ ${ }^{2}$ \\ Rosa Maria Stefanini de MACEDO
}

\begin{abstract}
Resumo
O presente trabalho teve como objetivo analisar projetos sociais voltados para jovens e seu impacto sobre as famílias. Partindo da ótica sistêmico-cibernética novo-paradigmática, com enfoque construcionista social, este estudo também levou em consideração o papel das redes sociais nas questões de saúde. Foi desenvolvida uma pesquisa qualitativa, com análise e interpretação do conteúdo de dezessete entrevistas, realizadas com sete profissionais, cinco jovens e cinco familiares. Nas entrevistas, identificou-se a necessidade de aproximar as famílias dos jovens que participam dos projetos, de forma que aumente não só o fortalecimento desses jovens, mas também de suas famílias e de suas redes sociais, ampliando sua participação social e possibilitando a redução da pobreza e da desigualdade.
\end{abstract}

Unitermos: Comunidade. Famílias. Jovens. Projetos sociais.

\begin{abstract}
The aim of this work was to study social projects geared towards young people and the impact of such projects on their families. Employing the systemic-cybernetic new paradigm and a social constructionist viewpoint, the study also considered the importance of social networks on people's health. Qualitative research was developed by analysing and interpreting seventeen interviews carried out with seven professionals, five young people and five family members. In the interviews, we identified the need to bring families closer to young people who participated in the projects in order to help empower theyoung people along with their families and social networks, increasing social participation and contributing to the reduction of poverty and social inequality in the country as a whole.
\end{abstract}

Uniterms: Community. Families. Youngsters. Social projects.

O interesse pelo tema nasceu da vivência das autoras que, tendo atuado em três projetos sociais, com diferentes propostas, objetivos e modelos de intervenção, identificaram diferentes demandas e necessidades - dos participantes, da equipe idealizadora, dos técnicos, da família e da comunidade - como pontos importantes a

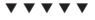

1 Artigo elaborado a partir da tese de M.R. FEIJÓ, intitulada "A Família e os projetos sociais voltados para jovens: impacto e participação". Pontifícia Universidade Católica de São Paulo, 2008. Apoio: Conselho Nacional do Desenvolvimento Científico e Tecnológico.

2 Pontifícia Universidade Católica de São Paulo, Núcleo da Família e Comunidade. R. Ministro Godoy, 969, 40 andar, Sala 4-05, Perdizes, 05015-001, São Paulo, SP, Brasil. Correspondência para/Correspondence to: M.R. FEIJÓ. E-mail: <marifeijo@uol.com.br>

Agradecimentos: Aos entrevistados e ao Conselho Nacional de Desenvolvimento Científico e Tecnológico, sem os quais este trabalho não seria possível. 
serem considerados não só em sua construção, mas também em sua realização e avaliação.

Nesse sentido, as demandas de famílias com alto índice de vulnerabilidade (Arpini \& Quintana, 2003; Ayres, Freitas, Santos, Saletti Filho \& França Júnior, 2003) ensejam um novo enfoque, de modo que os projetos sociais voltados para jovens sejam nelas embasados, para obter maior eficácia e abrangência (Cohen \& Franco, 1993). Além disso, as mudanças experimentadas pela família, durante o período de participação de um filho em determinado projeto social, exigem que se reflita sobre as futuras ações. De outro lado, observa-se que falta registrar e analisar, de forma crítica e sistemática, os resultados obtidos nos projetos sociais voltados para jovens, assim como se nota serem escassas as publicações sobre o impacto de tais projetos nas famílias dos participantes.

Muitos são os projetos sociais voltados para jovens, com vistas a melhorar sua condição de vida e a propiciar sua autonomia e protagonismo. Isso, porém, só será possível se a família e a rede de suporte ao jovem também alcançarem condições de vida no mínimo razoáveis e se, de alguma forma, acompanharem o projeto social em que ele está envolvido e sua possível aplicação na vida prática.

Assim, os objetivos deste trabalho foram: entender quando e como acontece uma mudança na vida e nas relações dos jovens que, participando de projetos sociais, adquirem novos conhecimentos e desenvolvem novas habilidades culturais, artísticas, esportivas ou que envolvam o uso de algum tipo de tecnologia, entre outras; apontar os aspectos (do projeto, do indivíduo, da família, da rede e do contexto) que facilitam ou dificultam tal crescimento; descrever como o projeto afeta os jovens, suas relações familiares e sua inserção nas instituições e comunidades de que fazem parte; apontar como os benefícios do projeto podem se tornar sustentáveis e duradouros, mesmo após o jovem deixá-lo.

Entende-se por "jovem"a pessoa que se encontra em transição entre a vida infantil e a adulta. Como critério de pesquisa, estabeleceu-se a faixa etária entre 14 e 20 anos no momento da entrevista, bem como a participação anterior em projeto social, dos 14 aos 18 anos. $O$ termo transição não deve ser entendido, porém, como transitoriedade (Losacco, 2003); refere-se apenas a uma

194 etapa do desenvolvimento, no qual o indivíduo não se considera e não é considerado nem como criança, nem como adulto. Entre 14 e 18 anos, é muito provável que o jovem já tenha entrado na puberdade; portanto, que tenha experimentado transformações biológicas e físicas, que sofra pressões para abandonar papéis e comportamentos infantis, que em alguns casos se prepare para o mercado de trabalho, e que não tenha sido emancipado, o que acarretaria outras questões.

"Projeto Social" são ações conjuntas e encadeadas que visam ao desenvolvimento social, a partir do trabalho com um grupo de pessoas. O projeto social voltado para jovens geralmente abarca atividades programadas para seu desenvolvimento, objetivando que viva melhor em seu meio social, que atue sobre ele e o transforme; portanto, que desenvolva maior autonomia e protagonismo, participando de forma efetiva e transformadora no meio ao qual pertence.

Partindo de uma base sistêmico-cibernética novo-paradigmática com ênfase nas relações e nas interações, com enfoque construcionista social (Esteves de Vasconcelos, 2002; Grandesso, 2000), este trabalho procura entender os indivíduos como autores que influenciam e ao mesmo tempo são influenciados pelo meio em que vivem, que constroem sua experiência e Ihe dão significado na linguagem do meio social a que pertencem.

Portanto, este estudo considera não só o contexto no qual está inserido seu objeto, mas também a relação das autoras com ele, na medida em que estas são parte integrante do que observam, pois interferem, modificam e ao mesmo tempo são modificadas pelo que observam. Desse ponto de vista, a equipe que executa o projeto, quando busca incrementar a autonomia e o protagonismo do indivíduo, ao mesmo tempo também se modifica e se transforma.

Esta pesquisa baseia-se ainda nos trabalhos sobre Redes Sociais, conforme proposto por Sluzki (1997), e nos estudos sobre o potencial de proteção, apoio e legitimação existente na relação com pessoas significativas (Aun, Vasconcelos \& Coelho, 2005; Dabas \& Najmanovich, 1995; Sluzki, 1997; Soares, Feijó, Valério, Siquieri \& Pinto, 2011). Elas expandem o interesse das redes pessoais e familiares para as redes de relação e sustentação, não só de indivíduos e famílias, mas também de instituições, bairros e comunidades, como apontam Moré e Macedo (2006). Acrescentam-se a essas 
as redes de serviços e equipamentos, as redes de informações e as redes de significados e interesses (econômicos, políticos), possibilitando a transformação de determinado segmento populacional (Acosta \& Vitale, 2003). Considera-se que o fortalecimento do indivíduo e de suas relações com as redes, sejam elas pessoais ou materiais, é ponto central na questão da saúde e do bem-estar, pois é em conjunto com o outro, e através das relações, que uma pessoa constrói a visão de si mesma (Campos \& Ferreira, 2007; Grandesso, 2000; Sluzki, 1997; White \& Epston, 1993). Assim, na relação com o outro, a pessoa se sente legítima e forte e encontra os recursos dos quais precisa para sobreviver, crescer e realizar-se. Considera-se ainda que para um ser humano só será possível usufruir os seus direitos básicos (alimentação, educação, saúde, trabalho e lazer) por meio da convivência e da participação social, especialmente para os mais carentes do ponto de vista material, razão pela qual é fundamental o apoio à família como matriz dessa socialização (Macedo,1994).

Autonomia e protagonismo, temas valorizados por teóricos da educação como Freire (2001) e por filósofos como Santos (2003), são vistos, neste trabalho, como fundamentais para a reversão da desigualdade social, na medida em que estão intimamente ligados à autopercepção do indivíduo, à força pessoal e à possibilidade de inclusão social. Ou seja, a possibilidade de atuar sobre determinado contexto dá ao indivíduo força para transformá-lo de acordo com seus valores e necessidades, de forma ativa e participativa.

"Autonomia"é definida operacionalmente neste estudo como a possibilidade de uma pessoa, família ou grupo crescer segundo suas necessidades, valores e expectativas; como a possibilidade de poder participar de redes sociais que the sejam importantes; de ser diferente dos demais e, ao mesmo tempo, sentir-se pertencer. Rebellato (2002), ao entender a autonomia como capacidade de autodeterminação e autocrítica, colocaa como uma capacidade fundamental a ser desenvolvida nos trabalhos comunitários, ponto de vista também adotado neste trabalho. Conforme Carvalho (2003), o indivíduo precisa ter autonomia material e psicológica para comunicar-se, seja em uma organização mais ampla, seja nos relacionamentos.

Já "protagonismo" é a atuação, de forma ativa, em busca do próprio bem-estar, o que envolve transfor- mações necessárias para alcançá-lo, seja na família, na escola, na sociedade. Assim, protagonismo é visto como participação social e como enfrentamento de situações e construção própria do ser social e pessoal (Costa, 2001); envolve, pois, proatividade.

Em um país como o Brasil, com enorme desigualdade social, elevados índices de analfabetismo e baixa qualidade do ensino, muitas pessoas têm dificuldades no uso da língua portuguesa, o que é mais um fator de exclusão. Nesse contexto, não é suficiente treinar e simplesmente dar instrumentos práticos, sem lidar com aspectos do desenvolvimento pessoal, como assertividade, autoestima, iniciativa, visão de si mesmo, relação com o próximo, percepção das necessidades da família e da comunidade. Essas pessoas, e também aquelas com as quais se relacionam, dependem de um contexto social, econômico, cultural e político que possa incrementar ou viabilizar o seu viver (Macedo, 1994; Sawaia, 2003; Szymanski,1995, 2002).

Até que ponto seria benéfico ampliar os horizontes dos jovens, fortalecê-los, deixando de fora sua família, o meio em que vive e que deve Ihe dar apoio afetivo e material? Se a família desconhece o que faz o jovem no programa, se não compreende quais benefícios concretos este pode trazer-lhe, se a frequência ao programa muitas vezes produz um distanciamento ainda maior entre o jovem e a família, pode-se perguntar: que amplitude social pode-se alcançar, considerando-se a enorme importância da família como rede significativa de apoio nessa fase da vida? Observa-se (Santos \& Macedo, 2008) que, ao deixar de lado a família, os programas correm o risco de enfraquecer a autoridade dos pais e colaborar para sua desqualificação perante o jovem.

Os projetos devem considerar que, mais do que informação e conhecimento, é necessária a formação de rede de apoio que inclua a família, no sentido de obter fortalecimento tanto emocional quanto material. Nesse sentido, este estudo entende que a família deve ser parte de todo projeto, por se constituir a base de pertencimento e legitimação social. O jovem pode transformar, ampliar e enriquecer a troca com o meio, devolvendo a ele o que adquiriu em conhecimento e agindo em seu favor. O meio pode favorecer, valorizar, apoiar, legitimar e viabilizar o seu crescimento contínuo, bem como manter uma troca, da qual as partes se 
beneficiem mutuamente. Quanto mais forem ao encontro dos interesses e necessidades das famílias, quanto mais envolverem as comunidades em que atuam, mais eficazes serão os projetos e mais qualidade apresentarão, na medida em que terão o reconhecimento público de sua utilidade.

O tema central desta pesquisa consiste em apontar de que maneira a família e a comunidade são influenciadas por determinados processos e como os influenciam, no âmbito dos projetos sociais. Qual é a dimensão qualitativa, ou marca, que um projeto social pode deixar nos envolvidos? Que relação existe entre a proposta do projeto e o crescimento do jovem? Que influência tem uma família, que participa do projeto, sobre o desenvolvimento do jovem?

\section{Método}

Foi realizada uma pesquisa qualitativa, por meio de entrevistas semiestruturadas com profissionais envolvidos em projetos sociais, com jovens participantes desses projetos por mais de um ano, e com seus familiares. Também foram realizadas entrevistas abertas com familiares e jovens que já tinham se desligado dos projetos, ou que não tinham participado, com o objetivo de que transmitissem livremente suas ideias e sugestões, sem se preocuparem com suas respostas ou temerem seu desligamento de um projeto ou Organização Não-Governamental (ONG).

Tal proposta possibilitou o diálogo e a co-construção com os entrevistados, incrementando o entendimento das diferenças existentes entre as famílias, os jovens e os profissionais envolvidos nos projetos, bem como as especificidades de cada um, de forma profunda e contextual (Denzin \& Lincoln, 1994). Foi uma tarefa complexa compreender quais dificuldades e ganhos viveram no processo e quais aspectos foram envolvidos, como a condição socioeconômica, as estruturas familiares e sociais, as influências culturais, além das questões do próprio projeto e da instituição. Por essa razão, entrevistas abertas foram realizadas, a fim de permitir o alcance dessa meta. Isso porque somente a partir do diálogo entre os participantes e os pesquisadores é que foi possível obter uma construção compartilhada sobre 196 o que eles viveram e sentiram naquele processo.
De acordo com a visão construtivista, com a hermenêutica contemporânea, com a dialética (Macedo, Kublikowski \& Grandesso, 2004; Minayo, 1996) e com a postura pós-moderna (Grandesso, 2000), a construção não é a única possível, nem a verdadeira (Kvale, 1994), mas sim um consenso entre as partes, que se dá através da linguagem. Ela está imersa em determinada cultura, permeada por valores e lentes individuais e é, portanto, uma visão construída durante o processo de pesquisa, iniciada nas reflexões do pesquisador e compartilhada e validada no decorrer do estudo.

Partiu-se, então, conforme objetivos citados, da hipótese de que projetos sociais bem estruturados, que ofereçam aos jovens algo que lhes desperte o interesse e seja realizado em grupo, trazem benefícios à maior parte deles e a sua família. Interessou estudar quais benefícios e mudanças podem ocorrer, bem como o eventual descompasso entre o crescimento/autonomia do jovem e sua inserção familiar.

O estudo de caso, a partir das entrevistas, com posterior análise qualitativa de dados em conjunto, foi necessário para que se levantassem as peculiaridades e as semelhanças das experiências relatadas, contextualizando-os nas condições dos jovens, das famílias e dos projetos estudados.

Realizou-se um estudo de caso coletivo (Stake, 1994), tanto para estudar cada caso, quanto para refletir sobre o que é comum a eles.

Buscando coerência com os pontos pesquisados, este estudo baseou-se na epistemologia sistêmico-cibernética, segundo o paradigma construtivista. Assim, pressupõe-se que o conhecimento é construído, e que tanto o participante da pesquisa quanto o pesquisador são partes desse processo de construção; que não existe uma realidade objetiva nem independente de quem a observa ou dela participa (Grandesso, 2000; Macedo, Kublikowski \& Grandesso, 2004; Esteves de Vasconcelos, 2002).

O projeto da pesquisa foi aprovado pelo Comitê de Ética em Pesquisa da Pontifícia Universidade Católica de São Paulo (PUC-SP), de acordo com o protocolo 15/2006. A pesquisa foi realizada segundo as diretrizes éticas para pesquisas com seres humanos, conforme a Resolução 196/96 do Conselho Nacional de Saúde. Assinaram o Termo de Consentimento Livre e Esclare- 
cido todos os participantes da pesquisa bem como os responsáveis pelas instituições.

\section{Participantes}

Este estudo constitui-se de 17 entrevistas, conduzidas pelas autoras, com pessoas envolvidas em projetos sociais voltados para jovens: profissionais, jovens e familiares. Foram realizadas 14 entrevistas semiestruturadas, assim distribuídas: 7 profissionais (à época atuantes em três projetos sociais, e com experiência anterior em mais de dez projetos: esportivos, culturais, de cidadania, liberdade assistida, inclusão digital, tutoria); 4 jovens e 3 familiares. Foram também realizadas 3 entrevistas abertas: uma com jovem e duas com familiares. Portanto, foram coletadas no mínimo cinco entrevistas com cada um dos grupos.

A seleção dos participantes foi feita por conveniência, tomando-se como critério que tanto os profissionais quanto os jovens por eles indicados para as entrevistas deveriam participar, ou ter participado, de um projeto social. Os jovens deveriam ter idade entre 14 e 20 anos na ocasião da pesquisa, e entre 14 e 18 anos quando frequentaram o projeto.

\section{Instrumentos}

A) Foram realizadas entrevistas semiestruturadas, individuais, com os profissionais de ONG e demais entidades, que trabalharam por mais de um ano em projetos sociais voltados para jovens. Tais entrevistas foram feitas para conhecer a proposta do projeto e seus objetivos, e também para ouvir a opinião dos profissionais sobre o impacto dos projetos nas famílias dos envolvidos. Pretendeu-se também levantar necessidades e demandas que eles teriam em relação ao campo, assim como avaliar se a pesquisa seria do interesse deles, e se o caminho planejado e as entrevistas com jovens e suas famílias estavam adequados.

B) Foram realizadas entrevistas semiestruturadas individuais com jovens entre 14 e 20 anos, que haviam participado de projeto social por no mínimo um ano, quando tinham idade entre 14 e 18 anos; e entrevistas com jovens nesta última faixa etária, que participavam ou tinham participado de projetos sociais cumprindo medida socioeducativa.
A conclusão de tal etapa permitiu entender como foi a entrada e a participação do jovem no projeto; que diferenças isso trouxe para a sua vida; se modificou suas relações, inclusive com a família, seus valores, sua visão de si mesmo e de suas possibilidades futuras.

C) Após a entrevista com o jovem que tinha participado ou participava do projeto social, foram feitas entrevistas individuais com os familiares, também de forma semiestruturada.

Essa última etapa da pesquisa de campo possibilitou entender como os familiares avaliam a participação do jovem no projeto: os benefícios para ele e para as relações familiares, eventuais impactos, dificuldades e mudanças ocorridas nas relações, na vida da família, na sua visão de si mesma e na visão em relação ao jovem (antes e depois da participação do projeto). Serviu ainda para ouvir a demanda e as necessidades da família e quais foram contempladas no projeto.

D) Após a análise parcial das entrevistas semiestruturadas, foi levantada a possibilidade de os jovens e famílias sentirem-se mais à vontade para falarem espontaneamente sobre os temas, em entrevistas abertas. Nessa etapa, foram entrevistados jovens e familiares, independentemente de estarem ligados a um projeto social, para ampliar os dados anteriormente obtidos.

\section{Estratégias}

Foi realizada pesquisa bibliográfica sobre ações sociais, pobreza, inclusão, globalização, famílias, ciclo vital familiar, rede social, sexo, etnia, configurações familiares, discriminação e preconceito, trabalhos sistêmicos na comunidade, projetos sociais e preventivos.

Entrevistas foram agendadas por indicações de profissionais que atuaram em projetos sociais (processo bola de neve). As entrevistas foram realizadas em local definido com os participantes, sendo gravadas mediante autorização por Termo de Consentimento. Para as entrevistas abertas, buscaram-se indicações de jovens e de seus familiares, que não pertencessem nem tivessem pertencido a alguma ONG.

\section{Análise das entrevistas}

A análise das entrevistas foi indutiva e recursiva, portanto feita tanto durante quanto após a realização das mesmas. 
As entrevistas foram gravadas em áudio, transcritas e analisadas com uma visão compreensiva, buscando padrões, singularidades e categorias de análise. Foi analisada a visão que os profissionais, os participantes e os familiares construíram do projeto e suas demandas. Em relação aos participantes, constatou-se que eles procuraram entender a visão que tinham de si mesmos, de suas relações, das possibilidades futuras após terem passado pelo projeto e vivenciado o seu processo direta ou indiretamente.

Os dados obtidos foram analisados de acordo com: a proposta de cada um dos projetos; a demanda da população; o interesse inicial do projeto; as características da comunidade e das instituições envolvidas; o suporte financeiro; e as condições socioeconômicas e culturais.

Após a análise de cada entrevista, foi feita a análise do caso, triangulando os dados das entrevistas com o profissional, com o jovem e com sua família, além dos dados do projeto do qual todos participaram, inclusive a família, indiretamente.

Em seguida foram vistos os casos em conjunto - estudo de caso coletivo, buscando-se entender os impactos que um projeto social pode trazer à família. Entende-se por "impacto", conforme Cohen e Franco (1993), o resultado dos efeitos do projeto. Não são exatamente os objetivos alcançados por este, mas o que resultou após suas ações, seus efeitos; o que houve com a família e entre ela e o jovem. Procurou-se compreender se projetos sociais podem resultar em melhora da autoestima e desenvolvimento do protagonismo dos jovens. Ou seja, a relação entre os objetivos, a proposta do projeto, seus efeitos e impactos, (Figura 1).

\section{Resultados e Discussão}

Os projetos foram avaliados positivamente e considerados úteis e importantes nos três grupos de entrevistados: profissionais, familiares e jovens. Boa parte dos entrevistados expressou, em diferentes momentos das entrevistas, que são necessárias mais vagas para os jovens em projetos sociais, o que reforça a importância que dão a eles.

Todos os entrevistados relataram mudanças no comportamento do jovem após o projeto, sendo as principais citadas: mudanças no relacionamento, aquisição de visão crítica e política, crescimento pessoal e profissional. O desenvolvimento foi expresso claramente pelos jovens.

\section{Sobre os benefícios para a família}

Os benefícios para a família foram identificados, porém todas as categorias relataram que os benefícios

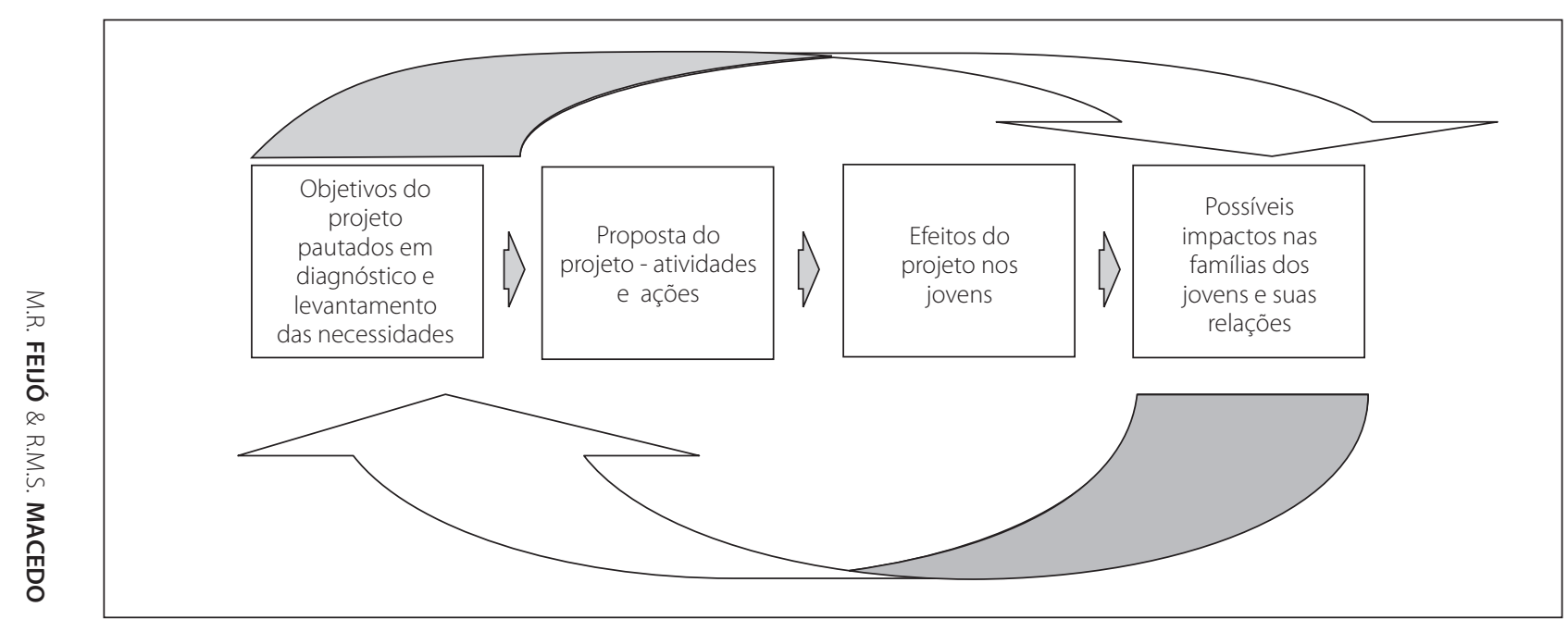

Figura 1. Objetivos, proposta, efeitos e impactos. 
foram indireto: o projeto beneficia a família, porque beneficia o jovem. Poucas, porém, foram as atividades contínuas direcionadas às famílias. Para os profissionais, isso se deve também às dificuldades de trazê-las aos eventos e atividades.

Os profissionais acreditam que as famílias têm ganhos com os projetos; que os familiares passam a ver o jovem de forma mais positiva e que recebem informações através dele. Muitos acham que ampliar a participação da família e aproximá-la do projeto é importante, mas não sabem como aumentar a sua participação. Outros acreditam saber como trabalhar com as famílias, mas também têm dificuldades para trazê-las à participação. Foi ressaltada a falta de recursos para viabilizar a vinda dos familiares, que também, muitas vezes, trabalham e não podem comparecer. Para alguns profissionais, parte das famílias não enxerga como oportunidade as atividades que lhes são propostas. Há também aqueles que não se sentem à vontade para participar, o que sugere baixo protagonismo, menor autonomia e pouca apropriação do serviço, além de um possível desencontro entre os recursos da família e a visão que os profissionais têm dela.

Segundo as mães entrevistadas, dentre os ganhos indiretos que as famílias recebem dos projetos está incluso o aumento de informações. Seus problemas familiares, tais como abuso de substâncias químicas e violência de outros membros da família, porém, continuam. Para elas, cursos e formação são importantes.

\section{Sobre a participação da comunidade e da família no projeto social}

A participação da comunidade nos projetos sociais não acontece como poderia acontecer. Apesar de muitos projetos nascerem a partir da iniciativa de um membro da comunidade ou próximo a ela, não foram relatadas muitas experiências de aproximação nem de participação de seus membros nos projetos estudados. Por outro lado, na comunidade há pessoas dispostas, disponíveis e com habilidades específicas, que poderiam ser úteis nos projetos, mas que não sabem como participar. Existem também, profissionais e jovens que aprovam a participação da família, mas que por diversos motivos não encontraram meios para viabilizar a participação dela. Para aqueles familiares que, por um pe- ríodo de tempo ou em determinada situação, participaram do projeto ou souberam como este funciona e com quais atividades, o resultado foi positivo, inclusive no apoio e valorização do mesmo.

Já em outras famílias, apesar de acharem o projeto útil e benéfico para o jovem, e apesar de sentirem segurança por ele não estar na rua, ainda há o desejo de que ele não se afaste de casa por longos períodos e, em alguns casos, de que trabalhe. A ajuda financeira para o sustento da família é esperada em parte dos lares. Por crença de que trabalhar é bom e importante, por falta de entendimento da proposta do projeto, por necessidade, ou por querer que o jovem colabore financeiramente, há ainda a pressão para que ele exerça atividade remunerada em algumas famílias.

Quando a família tem recursos para a própria sobrevivência, quando pode oferecer ao jovem um tempo para sua formação e o desenvolvimento, quando entende os objetivos do projeto, sua relação com este pode ser diferente. No entanto, isso também pode depender de outros fatores, como composição familiar, momento de vida (ciclo vital familiar), estabilidade e qualidade das relações familiares, além das características do próprio jovem, suas motivações e interesses.

\section{Sobre a possibilidade de transformação social}

Por outro lado, ficou evidente que uma transformação social depende do fortalecimento da autonomia e da participação da família, que, em geral, é muito necessitada e sem acesso aos bens sociais. Apenas um profissional salientou que a ação do jovem, por si só, pode trazer transformação, muito embora esse mesmo profissional tenha considerado importante a participação da família no projeto.

Se a família ao menos souber do que trata o projeto e como é conduzido, é possível que estimule a participação do jovem e procure acompanhar seu desenvolvimento. Acompanhar, geralmente, faz buscar conhecimento, faz refletir sobre si mesmo, sobre sua participação social e sobre seus direitos, especialmente nos projetos que têm como eixo a cidadania.

Parte dos entrevistados ressaltou que o fato de a família colaborar e participar do projeto traz ganhos para todos. Tanto pelo uso da linguagem, quanto pela 
importância que atribuem às atividades e conteúdos dos projetos, os familiares que tiveram participação neles distinguem-se dos que não participaram e demonstram também maior propriedade na discussão sobre projetos e necessidades da comunidade.

O projeto social pode ser então, uma parte do processo de desenvolvimento social, contribuindo para a reversão do quadro de desigualdade, pela conquista de relações equânimes, pois, se um grupo leva seu conhecimento ao outro e o inclui em suas ações, todos saem ganhando, afinam a linguagem, apropriam-se de seus direitos e fortalecem-se.

\section{Sobre as demandas}

Trabalhar para construir algo que venha ao encontro das necessidades mais amplas da população mostrou-se um ponto muito importante, donde a necessidade de se observarem as demandas familiares, as quais geralmente refletem demandas sociais.

Segundo as mães, é necessário mais trabalho, mais estudo, mais faculdades e mais vagas em projetos sociais para jovens. Um dos jovens acredita que ações e atividades para as famílias são importantes para a comunidade, outro acredita que devam ser oferecidos mais esporte, cultura e cursos profissionalizantes. A ques-tão financeira e a oferta de trabalho também aparecem frequentemente relacionadas às principais demandas expressadas.

O conflito entre o jovem e o adulto aparece em muitas respostas. Alguns colocam claramente que acreditam que a comunidade não quer o jovem nas ruas "aprontando"; que a família quer sossego e jovens bem comportados; porém, quase todos dizem que seria bom se eles estivessem trabalhando, buscando trabalho ou, no mínimo, preparando-se para o mercado de trabalho.

Nas famílias aqui estudadas, além das preocupações de quem vê o filho alçando voo e arriscando, há a forte presença da violência, o medo do tráfico, da gravidez precoce e não planejada, do uso de drogas; um medo de quem se enxerga com poucos recursos para oferecer ao filho alternativas a esses caminhos considerados maus; de quem acredita que pouco poderá fazer para tirá-los deles ou evitar que entrem neles. Portanto, observa-se que, no caso das famílias em situação de "exclusão"3 social e pobreza material, as demandas de subsistência ea necessidade de resistência (em relação aos preconceitos, à discriminação, à violência e às adversidades frequentes) sobrepõem-se, melhor dizendo, cruzam-se com as demandas do ciclo vital familiar e individual. Ou seja, as necessidades dessa população estão relacionadas com o contexto em que vive, sem que isso exclua individualidades e singularidades, como em qualquer grupo ou família que compartilha de algo que é socialmente construído (Sawaia, 1999).

No caso dessas famílias, as situações extremas de risco, a violência e a carência, precisam ser olhadas com bastante flexibilidade: não como algo imutável, estigmatizante, idealizado, mas como algo a ser transformado e cuidado.

De maneira geral, na questão sobre as necessidades da população, os itens mais citados foram emprego e trabalho, seguidos de educação, cursos, formação e capacitação, que também apareceram com grande frequência.

\section{Considerações Finais}

As entrevistas mostraram que o jovem - principalmente quando interessado e quando é autor na escolha do tipo de projeto de que participará - muito se beneficia e se desenvolve com ele, levando parte dos benefícios para a vida familiar. Nessas condições, foram citadas mudanças positivas no comportamento e no relacionamento do jovem com a família e com a rede de pessoas que o cerca. Foram vistos como muito positivos impactos familiares como melhora na comunicação do jovem com a família, melhora no seu relacionamento com parentes e vizinhos, e melhora na sua participação social, segundo relatos de alguns entrevistados.

Melhor seria que tais conquistas fossem alcançadas, sem diminuir a importância da família e sem

\section{0}

$\operatorname{cov} \sin$

3 O termo exclusão é usado entre aspas, uma vez que, como bem discutiu Sawaia (1999), todas as pessoas são parte de determinados segmentos sociais, portanto incluídas e excluídas sempre. 
desconsiderar a vida familiar do jovem, uma vez que a autonomia deste também depende da autonomia de sua família e do meio em que vive. Nesse sentido, insiste-se, é importante que o projeto não seja um meio de criar distância entre o jovem e a família ou de reforçar sua exclusão. A família pode participar do projeto de diferentes maneiras: conhecendo seus objetivos e funcionamento, ela pode acompanhar seu andamento, seja conversando sobre ele com o jovem, seja cobrando resultados. A família pode também partilhar planos de futuro com o jovem e acompanhar o seu desenvolvimento.

Espaços de escuta para a família podem ser muito importantes, no sentido de conhecer suas necessidades e demandas, evitando vieses e preconceitos. No entanto, pelos resultados obtidos, viu-se que os familiares nem sempre são envolvidos e, muitas vezes, quando o são e não conseguem participar, tornam-se alvo de estigma e críticas, sendo tachadas de "desinteressadas" ou "desestruturadas", muito embora nunca tenham tido espaço para se colocar. Há que se construir narrativas mais positivas sobre as famílias; narrativas baseadas na ideia de que todos têm algumas habilidades e possibilidades; que permitam abertura, e não manutenção de preconceitos, haja vista as colocações feitas por alguns profissionais. Não se pode reforçar a ideia de que "a família está comprometida" por falta de valores. Cada família tem seus valores, sua cultura e sua força. Melhor poderão ser vistas as potencialidades dos jovens e os recursos de suas famílias, partindo-se de seus próprios valores e buscando-se construir conjuntamente valores que promovam a proatividade na direção da justiça social, evitando-se as atitudes meramente assistencialistas.

A educação, além de ser primordial para o desenvolvimento humano e social, foi destacada pelos jovens como necessária. A comunicação e o domínio da linguagem são fatores decisivos no desenvolvimento do ser humano e na busca por maior equidade nas relações sociais. Os jovens que tiveram acesso aos projetos de comunicação apresentaram grande desenvoltura, participação social e visão crítica, além de melhor preparo para entrar no mercado de trabalho.

É necessário atuar em diversas frentes, com visão transdisciplinar, buscando melhorias na saúde, na área social, na educação, tanto no âmbito individual (crianças, jovens, adultos de todas as idades) como no familiar e no coletivo. Para isso, há que se perguntar sempre o que as pessoas querem; acreditar que elas sabem o que é bom para si; humanizar os serviços; atender cada vez melhor, de forma organizada, planejada, sem autoritarismo. Educar, para que as pessoas possam cuidar de si e do mundo no qual vivem, preservando suas relações e diálogos, reforçando e desenvolvendo valores positivos no que se refere ao respeito a si mesmo, ao outro e ao meio ambiente.

As práticas voltadas ao desenvolvimento humano devem ser, portanto, coconstruídas e dinâmicas, além de participativas e com foco na melhoria do meio, incluindo o micro e o macrocontexto: o indivíduo, a família, a comunidade e o meio social. Todos devem responsabilizar-se por elas: o Estado, a família e os indivíduos em parceria, seja de forma autônoma ou institucionalizada.

\section{Referências}

Acosta, A. R., \& Vitale, M. A. (Orgs.). (2003). Família: redes, laços, políticas públicas. São Paulo: PUC-SP.

Arpini, D. M., \& Quintana, A. M. (2003) Identidade, família e relações sociais em adolescentes de grupos populares. Estudos de Psicologia (Campinas), 20 (1) 27-36. doi: 10.15 90/S0103-166X2003000100003.

Aun, J., Vasconcelos, M. J., \& Coelho, S. V. (2005). Atendimento sistêmico defamílias eredes sociais. Belo Horizonte: Ophicina de Arte e Prosa.

Ayres, J. R., Freitas, A. C., Santos, M. A., Saletti Filho, H., \& França Junior, I. (2003). Adolescência e aids: avaliação de uma experiência de educação preventiva entre pares. Interface: Comunicação, Saúde, Educação, 7 (12), 123-38.

Campos, G. M., \& Ferreira, R. F. (2007). A importância da legitimação social na (re) construção da identidade de um alcoolista. Estudos de Psicologia (Campinas), 24 (2) 215-225. doi: 101590/S0103-166X2007000200008.

Carvalho, M. C. B. (Org.). (2003). Famílias e políticas públicas. In A. R. Acosta \& M. A. Vitale (Orgs.). Famílias: redes, laços e políticas públicas (pp.255-271). São Paulo: PUC-SP.

Cohen, E., \& Franco, R. (1993). Avaliação de projetos sociais. Petrópolis: Vozes.

Costa, A. C. (2001). Tempo de servir: o protagonismo juvenil passo a passo, um guia para o educador. Belo Horizonte: Universidade.

Dabas, E., \& Najmanovich, D. (Orgs.). (1995). Redes:ellenguage delos vinculos hacia la reconstrucion yel fortalecimento de la sociedade civil. Buenos Aires: Paidos.

Denzin, N., \& Lincoln, Y. (1994). Introduction: entering the field of qualitative research. In N. Denzin \& Y. Lincoln (Eds.), Handbook of qualitative research (pp.1-17). Thousand Oaks, CA: Sage. 
Esteves de Vasconcelos, M. J. (2002). Pensamento sistêmico: o novo paradigma da ciência. Campinas: Papirus.

Feijó, M. R. (2008). A família e os projetos sociais voltados para jovens: impacto e participação. Tese de doutorado nãopublicada, Programa de Pós-Graduação em Psicologia, Pontifícia Universidade Católica de São Paulo.

Freire, P. (2001). Direitos humanos e educação libertadora. In A. M. Freire Araújo (Org.), Pedagogia dos sonhos possíveis (pp.98-99). São Paulo: Unesp.

Grandesso, M. (2000). Sobre a reconstrução do significado: uma análise epistemológica e hermenêutica da prática clínica. São Paulo: Casa do Psicólogo.

Kvale, S. (1994). Ten standard objections to qualitative research interviews. Journal of Phenomenological Psychology, 25 (2), 147-173.

Losacco, S. (2003). O jovem e o contexto familiar. In A. Acosta \& M. A. F. Vitale (Orgs.), Famílias: redes, laços e políticas públicas (pp.63-76). São Paulo: PUC-SP.

Macedo, R. M. (1994). A Família do ponto de vista psicológico: lugar seguro para crescer? Caderno de Pesquisas, 91 (2), 62-68.

Macedo, R., Kublikowski, I., \& Grandesso, M. (2004). A Interpretação em pesquisa qualitativa: a construção do significado. Anais da I CIBRAPEQ - Conferência Internacional do Brasil de Pesquisa Qualitativa. Taubaté

Minayo, M. C. S. (1996). O Desafio do conhecimento: pesquisa qualitativa em saúde (4a ed.). São Paulo: Hucitec-Abrasco.

Moré, C., \& Macedo, R. M. (2006). A psicologia na comunidade: uma proposta de intervenção. São Paulo: Casa do Psicólogo.

Rebellato, J. L. (2002). Horizontes de un paradigma emancipativo: su articulación con la práctica. In Psicología para América Latina. Recuperado em junho 2,2007, disponível em <http://www.psicolatina.org/Cero/horizontes.html>
Santos, B. (2003). Reconhecer para libertar: os caminhos do cosmopolitismo multicultural. Rio de Janeiro: Civilização Brasileira.

Santos, J. L., \& Macedo, R. M. (2008). Valores familiares e educação dos filhos na contemporaneidade. In R. M. Macedo (Org.), Terapia familiar no Brasil na última década (pp.169-179). São Paulo: Roca.

Sawaia, B. (Org). (1999). Artimanhas da exclusão: análise psicossocial eética da desigualdade social. Petrópolis: Vozes.

Sawaia, B. (Org.). (2003). Família e afetividade: a configuração de uma práxis ético-política, perigos e oportunidades. In A. R. Acosta \& M. A. Vitale (Orgs.), Famílias: redes, laçose políticas públicas (pp.39-50). São Paulo: PUC-SP.

Sluzki, C. (1997). A rede social na prática sistêmica. São Paulo: Casa do Psicólogo.

Soares, M., Feijó, M. R., Valério, N. I., Siquieri, C. L. S. M., \& Pinto, M. J. C. (2011). O apoio da rede social a transexuais femininas. Paidéia, 21 (48), 83-92.

Stake, R. (1994). Case Studies. In N. Denzin \& Y. Lincoln. Handbook of qualitative research (pp.236-247). Califórnia: Sage Publications.

Szymanski, H. (1995). Teorias e "teorias" de famílias. In M. C. Carvalho (Org.), A familia contemporânea em debate (pp.23-27). São Paulo: EDUC.

Szymanski, H. (2002). A Família como locus educacional. Revista Brasileira de Estudos Pedagógicos, 81 (197), 14-25.

White, M., \& Epston, D. (1993). Medios narrativos para fines terapéuticos. Barcelona: Paidós.

Recebido em: 3/8/2009

Versão final reapresentada em: 16/11/2011

Aprovado em: 2/12/2011 